\title{
Density functional theory (DFT) and time-dependent density functional theory (TDDFT) studies of selected ancient colourants as sensitizers in dye-sensitized solar cells
}

\author{
Muhammad Raziq Rahimi Kooh, Voo Nyuk Yoong and Piyasiri Ekanayake* \\ Applied Physics Programme, Faculty of Science, Universiti Brunei Darussalam, Jalan Tungku Link, BE1410, Negara Brunei Darussalam.
}

Revised: 31 October 2013; Accepted: 27 November 2013

\begin{abstract}
Ancient dyes such as brazilin, brazilein, haematoxylin and haematein have wide applications such as dyestuff, microscopy stains, and also as traditional and modern medicines. However these dyes have not yet been explored as sensitizers in dye sensitized solar cells. In the present work theoretical studies of these dyes have been performed using concepts such as density functional theory and time-dependent density functional theory, with Gaussian'09W software at B3LYP/6-31g(d) level. All the calculations are with the inclusion of geometric optimization and solvation effect of ethanol. Various energy levels of the dyes, electron cloud density, dominant energy transition states, optical properties and deprotonation order (proton affinity) of the dyes were obtained. This information was helpful to evaluate the feasibility of the dyes in dye sensitized solar cell (DSSC) applications. The dominant energy transition state of all dyes was found to be HOMO $\rightarrow$ LUMO at the first excitation state. For all four dyes electron clouds at the lowest unoccupied molecular orbital (LUMO) level were found to be localized near or at the most probable hydroxyl group that may anchor to the semiconductor. Among the four dyes, brazilein and haematein displayed excellent optical properties ( $\lambda$ max, oscillator strength, absorption band at visible spectrum) exhibiting their potential in DSSC application.
\end{abstract}

Keywords: Brazilein, brazilin, DFT, DSSC, haematein, haematoxylin.

\section{INTRODUCTION}

Dye-sensitized solar cells (DSSC) are solar devices that convert light energy into electrical energy and have received much attention, research and development due to the low cost, high efficiency and the ease of preparation (Liu, 2008; Wang et al., 2013). The solar cell was first reported by O'regan and Grätzel (1991). The highest photon-conversion efficiency was achieved by Yella and co-workers (2011) at $12 \%$.

A DSSC consists of a photo-sensitizer (dye), an electrolyte (contain redox couple), metal oxide semiconductors and a counter electrode. An ideal dye relevant to DSSC application should possess the ability to be excited to the lowest unoccupied molecular orbital (LUMO) level by visible light, anchor strongly onto the metal oxide semiconductor (typically by the hydroxyl group or carboxyl group), and inject electrons into the semiconductor where the electrons will then flow into the external load (Calogero et al., 2013; Wang et al., 2013).

Many natural dyes and pigments have been extracted from flowers (e.g. Bougainvillea, Hibiscus); leaves (e.g. spinach, holly); fruits (e.g. dragon fruit); and seeds (e.g. coffee) during the past decades, used as photosensitizers and tested for the photon-to electrical conversion efficiency in the DSSC research (Narayan, 2012).

Brazilin (C.I 75280) and haematoxylin (C.I 75290) are some of the natural colourants that have been used in the Mediterranean region thousands of years ago (Melo, 2009). Brazilin was reported to be identified in centuriesold textile samples found in the Mount Athos, Greece (Karapanagiotis et al., 2011), and the historical uses as dyestuff and traditional medicines were well-described by Puchtler and co-workers (1986). In the past decades brazilin, haematoxylin and its derivative forms have 
been widely used as microscopy stains for biological samples (Puchtler et al., 1986) and for colourimetric detection of metals such as tin, aluminium and molybdate (Sastry et al., 1989). In the recent years these dyes have been widely studied in pharmaceutical research, which includes uses as anti-convulsant (Baek et al., 2000), immunosuppressant (Ye et al., 2006), anti-inflammatory drug (Wu et al., 2011), as well as in HIV (Ishii et al., 2012) and cancer drug research (Kim et al., 2012).

Brazilin is extracted from red wood such as Caesalpinia brasiliensis, C. echinata and C. sappan, and haematoxylin is extracted from Haematoxylum campechianum (Puchtler et al., 1986; Melo, 2009; Ishii et al., 2012; Tong et al., 2014). The molecular structure of brazilin and haematoxylin are almost similar, with haematoxylin possessing one hydroxyl group more than brazilin (Figure 1). Both brazilin and haematoxylin can be oxidised in lye, alkaline solutions or by oxidizing agents to yield brazilein and haematein, respectively (Livingstone, 1987; Ishii et al., 2012). Brazilin and haematoxylin are not considered as dyes under treatises on staining (Culling, 1963; Puchtler et al., 1986) because both dyes are colourless when in pure form (Weigl et al., 2009). However, the oxidized forms of brazilin and haematoxylin are coloured (Rosenberg, 2008).

So far brazilin, haematoxylin and their oxidized forms have not been explored for DSSC applications. Moreover, these dyes possess hydroxyl groups, which can serve as an anchoring group to the semiconductor (Calogero et al., 2013). The main aim of this theoretical
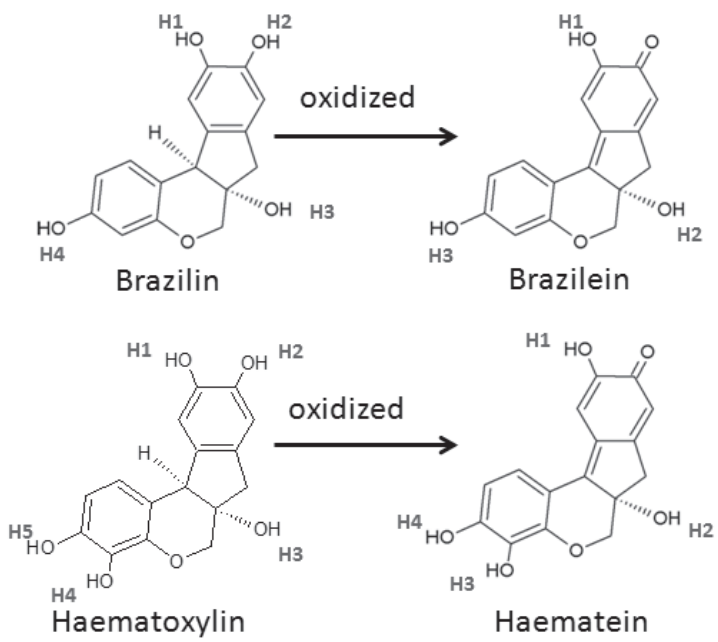

Figure 1: Molecular structure of brazilin, brazilein, haematoxylin and haematein. The hydroxyl groups of the dyes are labelled as $\mathrm{H} 1, \mathrm{H} 2, \mathrm{H} 3, \mathrm{H} 4$ and $\mathrm{H} 5$. study was to investigate the possibility of using such dyes as photo-sensitizers in DSSC applications.

\section{COMPUTATIONAL DETAILS}

Spartan'10 software package was used for constructing the structure of the molecules and obtaining the molecular geometric coordinates (Deppmeier et al., 2011). Both density functional theory (DFT) and time-dependent density functional theory (TDDFT) calculations were carried out using Gaussian'09W software package (Frisch et al., 2010). B3LYP hybrid functional and 6-31g(d) basis set were applied to DFT and TDDFT calculation. Molecular geometric optimizations were carried out using B3LYP/6-31g(d) level of theory with the inclusion of solvation effect of ethanol. The molecular orbital plots were visualised at isovalue of density of 0.03 using GaussView Version 5 (Dennington et al., 2009). Deprotonation order (proton affinity) was performed using B3LYP/6-31g(d) levels in gas phase (without solvation effect).

\section{RESULTS AND DISCUSSION}

\section{Energy levels}

The main reason for including the solvation effect of ethanol in the calculation is because brazilin and haematoxylin are extracted in ethanol from redwood samples (Ye et al., 2006). Table 1 summarizes the results of DFT and TDDFT calculations of the dyes with the inclusion of geometric optimization and solvation effect of ethanol at B3LYP/6-31g(d) level of theory.

DFT calculates the energy levels of the dye molecule at particular transition states. The band gap of brazilein and haematein were $2.94 \mathrm{eV}$ and $2.95 \mathrm{eV}$, respectively, whereas brazilin and haematoxylin were $5.47 \mathrm{eV}$ and $5.45 \mathrm{eV}$. The similarities of the energy levels (brazilin $v s$ haematoxylin, and brazilein $v s$ haematein) may be due to their similar molecular structures (Figure 1).

The highest occupied molecular orbital (HOMO) and the lowest unoccupied molecular orbital (LUMO) energy levels of the oxidized dyes (brazilein and haematein) were almost equal, while a similar pattern was observed for energy levels of non-oxidized dyes (brazilin and haematoxylin).

For efficient injection of the electron of the excited dye into the metal oxide semiconductor e.g. $\mathrm{TiO}_{2}$, the LUMO level of the dye needs to be higher than the conduction band edge of the semiconductor (Lee \& Yang, 
Table 1: DFT and TDDFT calculation of the dyes with inclusion of geometric optimization and solvation effect of ethanol at B3LYP/6-31g(d) level of theory.

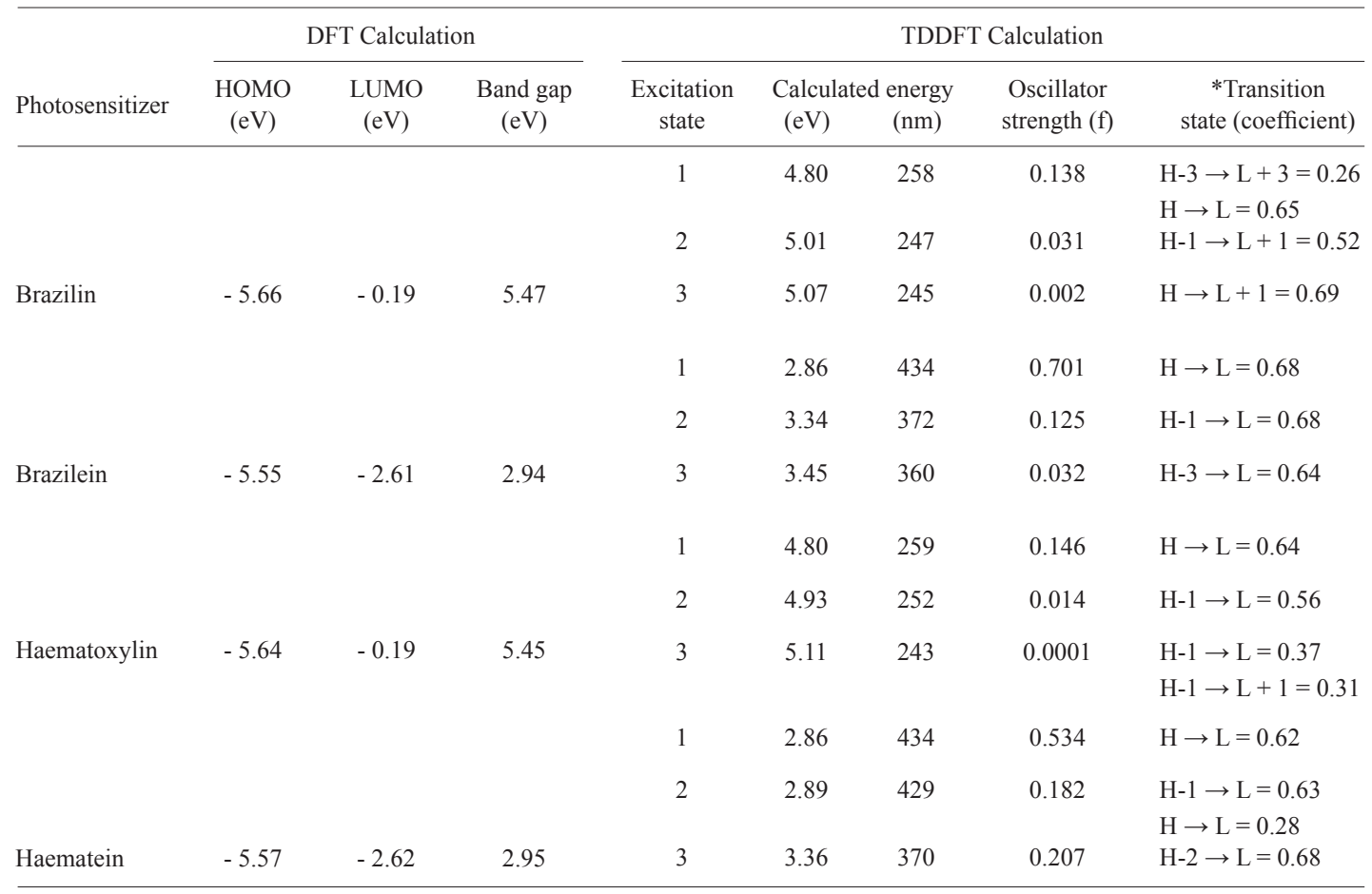

*Coefficients higher than 0.2 were only listed in the table

2011; Calogero et al., 2013). The band edge of $\mathrm{TiO}_{2}$ is approximately at $-4.2 \mathrm{eV}$ (relative to vacuum) (Heera \& Cindrella, 2010) and the LUMO energy level of brazilin, haematoxylin, brazilein and haematein were $-0.19 \mathrm{eV}$, $-0.19 \mathrm{eV},-2.61 \mathrm{eV}$ and $-2.62 \mathrm{eV}$, respectively, indicating that the LUMO levels of all four dyes are higher than the conduction band edge of $\mathrm{TiO}_{2}$.

The HOMO level of the dye needs to be sufficiently lower than the redox couple to ensure the efficient regeneration of the dye (Calogero et al., 2013). The most widely used redox couple in the electrolyte of DSSC is the $\mathrm{I}^{-} / \mathrm{I}^{3-}$ pairs where the estimated energy level is at $-4.8 \mathrm{eV}$ (relative to vacuum) (Lee \& Yang, 2011). The HOMO of brazilin, haematoxylin, brazilein and haematein were - $5.66 \mathrm{eV},-5.64 \mathrm{eV},-5.55 \mathrm{eV}$ and $-5.57 \mathrm{eV}$, respectively, which are more negative than the energy level of the redox couple.

\section{Optical properties}

TDDFT calculation simulated the optical properties of the dyes. The first excitation state of all four dyes were predominantly a HOMO $\rightarrow$ LUMO transition $\left(\pi \rightarrow \pi^{*}\right.$ type electron cloud transition), and all yield the highest oscillator strength (Table 1, Figure 2). The energy transition for the second excitation state is HOMO - $1 \rightarrow$ LUMO, while at the third excitation state, all four dyes displayed different energy transition states.

The absorption bands of both brazilin and haematoxylin were in the UV region, whereas brazilein and haematein absorption bands were at the visible spectrum region. The estimated molar extinction coefficient $\varepsilon$ of brazilin, brazilein, haematoxylin and haematein were $6600,30200,6400$ and $31000 \mathrm{M}^{-1} \mathrm{~cm}^{-1}$, and the peak absorbance maxima $\lambda_{\max }$, were $258 \mathrm{~nm}$, $434 \mathrm{~nm}, 259 \mathrm{~nm}$ and $434 \mathrm{~nm}$, respectively. The oxidized analogues of the dyes (brazilein and haematein) were observed to produce stronger absorption bands than the non-oxidized dyes (brazilin and haematoxylin).

Both brazilin and haematoxylin were reported to have the same $\lambda_{\max }$ at $292 \mathrm{~nm}$ (experimental UV-vis data). Thier oxidized analogues (brazilein and haematein) were reported to have their $\lambda_{\text {max }}$ at $445 \mathrm{~nm}$ (Bettinger \& Zimmermann, 1991; Dong et al., 1997; Gulmini et al., 2013). The suggested reason for brazilin and haematoxylin to have the same UV-vis absorption maxima may be due to the similarity in the chemical structure (Figure 1), and the same reason is suggested for the oxidized analogues of the dyes. These reported experimental UV-vis data 
are close to the theoretical values obtained by TDDFT calculation. Furthermore, the absorption band pattern of the experimental UV-vis absorption spectra of both haematoxylin and haematein (not shown here) (Bettinger \& Zimmermann, 1991) resemble the UV-vis absorption spectra (Figure 2) derived from TDDFT.

Oscillator strength $f$, is the strength of the transition of the dye from one energy state to another (i.e. from HOMO to LUMO) and is related to light harvesting efficiency (LHE) (Wang et al., 2013). The value of the oscillator strength determines the capability of the dye as a photo-sensitizer. A higher oscillator strength indicates the more usefulness of the dye as a photo-sensitizer (Heera \& Cindrella, 2010). The oscillator strength (at first excitation state) of brazilein and haematein were 0.701 and 0.534 , respectively, while brazilin and haematoxylin were 0.138 and 0.146 . At the second and third excitation states, the oscillator strength of all four dyes were much lower than at the first excitation state. It was deduced that the oxidized dyes (brazilein and haematein) are better photo-sensitizers than non-oxidized dyes (brazilin and haematoxylin).

\section{Deprotonation (proton affinity)}

Deprotonation is the energy difference between the optimized protonated and deprotonated molecules, usually calculated in the gas phase. No solvation effect is included in the calculation because the solvation sphere is artificially restricted (Qin \& Clark, 2007; Liu, 2008).

The hydroxyl (-OH) group and the carboxyl group $(-\mathrm{COOH})$ are the two common functional groups of a natural dye that anchors the dye molecules to the metal oxide semiconductor such as $\mathrm{TiO}_{2}$ (Heera \& Cindrella, 2010; Calogero et al., 2013). By calculating the proton affinity, it can be determined as to which of the hydroxyl groups of a dye is the most probable anchor group. The group with the lowest value of the proton affinity indicates the most probable group that anchors to the metal oxide semi conductor (Qin \& Clark, 2007; Heera \& Cindrella, 2010).

Brazilin molecule contains four hydroxyl groups. The deprotonation order of brazilin starting from the lowest energy value was $\mathrm{H} 2<\mathrm{H} 1 \approx \mathrm{H} 4<\mathrm{H} 3$ (Table 2). As $\mathrm{H} 2$ of brazilin has the lowest energy, it is the most probable anchoring group. Brazilein contains only three hydroxyl groups, and the deprotonation order was $\mathrm{H} 3<$ $\mathrm{H} 1<\mathrm{H} 2$, thus $\mathrm{H} 3$ is the most probable anchoring group of brazilein.

Haematoxylin contains five hydroxyl groups, and the deprotonation order is $\mathrm{H} 2<\mathrm{H} 5<\mathrm{H} 1<\mathrm{H} 4<\mathrm{H} 3$. The most probable anchoring group is $\mathrm{H} 2$. The deprotonation energy values of $\mathrm{H} 2$ and $\mathrm{H} 5$ are close (difference of $5.2 \mathrm{Kcal} \mathrm{mol}^{-1}$ ), and thus $\mathrm{H} 5$ may also be favourable as an anchoring group. Haematein contains four hydroxyl groups and the deprotonation order is $\mathrm{H} 4<\mathrm{H} 3<\mathrm{H} 1<\mathrm{H} 2$. The most probable anchoring group of haematein is $\mathrm{H} 4$.

\section{Electronic structure}

The model of electronic structure of the dyes as seen in Figure 3, displays the density of the electron clouds at different energy levels. The information regarding where the electron clouds are concentrated will be useful to predict whether the electron transfer system is efficient. Brazilin molecule consists of two major units, which are the 3,4-dihydro-2H-chromen-3,7-diol unit (CMD) and the 2,3-dihydro- $1 H$-indene-5,6-diol unit (IDD) (Figure 1). At HOMO - 1 level, the $\pi$-type electron cloud was localized in the CMD unit, while at HOMO level, the $\pi$-type electron clouds shifted to the IDD unit (Figure 3). At LUMO level, the $\pi^{*}$-type (anti-bonding) electron clouds delocalized over the entire molecules, with much denser electron clouds localized at the IDD unit. LUMO - 1 level displayed the same electron cloud pattern as LUMO level, except that denser electron clouds were found to localize in the CMD unit. As previously mentioned the first excitation state of the dye is a HOMO $\rightarrow$ LUMO transition. The injection of electrons to the metal oxide semiconductor is mostly facilitated by the dense electron clouds localized near to the anchoring group (H2 hydroxyl group) at the LUMO level.

Brazilein dye consists of a CMD unit and a 6-hydroxyl2,3-dihydro-5H-inden-5-one unit (HDI). At HOMO - 1 and HOMO level, $\pi$-type electron clouds were observed to delocalize over the entire molecule. At LUMO level, the delocalization of $\pi^{*}$-type electron clouds over the entire molecules were observed. The electron cloud covering the anchoring group (H3 hydroxyl group) at LUMO level can facilitate the injection of the electrons into the metal oxide semiconductor. At LUMO - 1 , the $\pi *$-type electron clouds delocalized over the entire molecule, and a higher density of electron cloud is observed at the CMD unit.

Table 2: Energy values of the deprotonation order (proton affinity) of the oxidized and non-oxidized dyes in Kcal mol ${ }^{-1}$

\begin{tabular}{lccccc}
\hline \multirow{2}{*}{ Sensitizers } & \multicolumn{5}{c}{ Deprotonation order $\left(\mathrm{Kcal} \mathrm{mol}^{-1}\right)$} \\
& $-\mathrm{H}^{+}$ & $-\mathrm{H} 2^{+}$ & $-\mathrm{H}^{+}$ & $-\mathrm{H}^{+}$ & $-\mathrm{H} 5^{+}$ \\
\hline Brazilin & 341.1 & 326.1 & 358.1 & 341.7 & \\
Brazilein & 334.1 & 344.0 & 313.0 & & \\
Haematoxylin & 341.7 & 326.7 & 359.9 & 347.0 & 331.9 \\
Haematein & 334.8 & 345.0 & 330.2 & 306.2 & \\
\hline
\end{tabular}




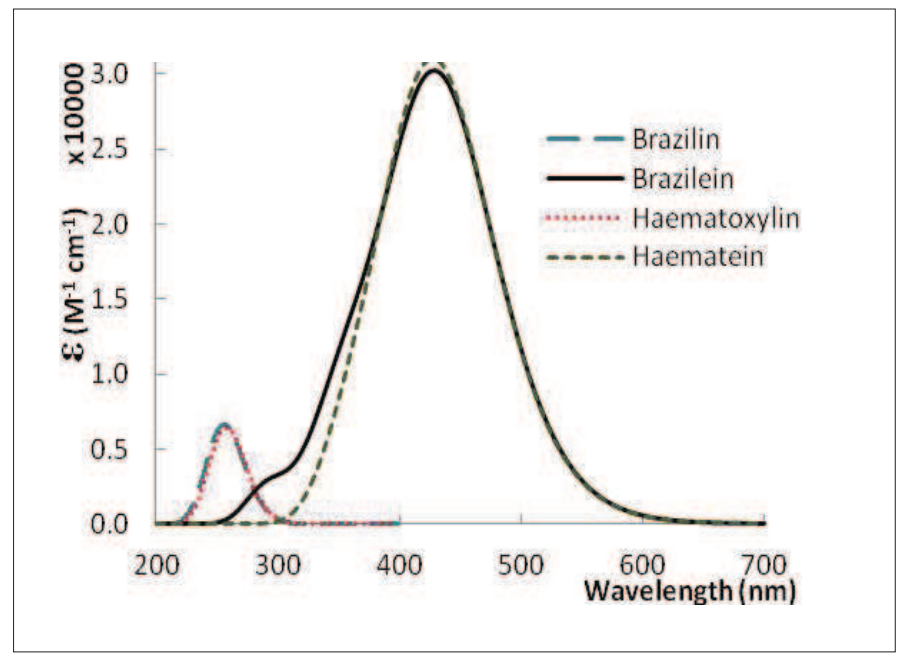

Figure 2: Simulated UV-vis absorption spectra of brazilin, brazilein, haematoxylin and haematein
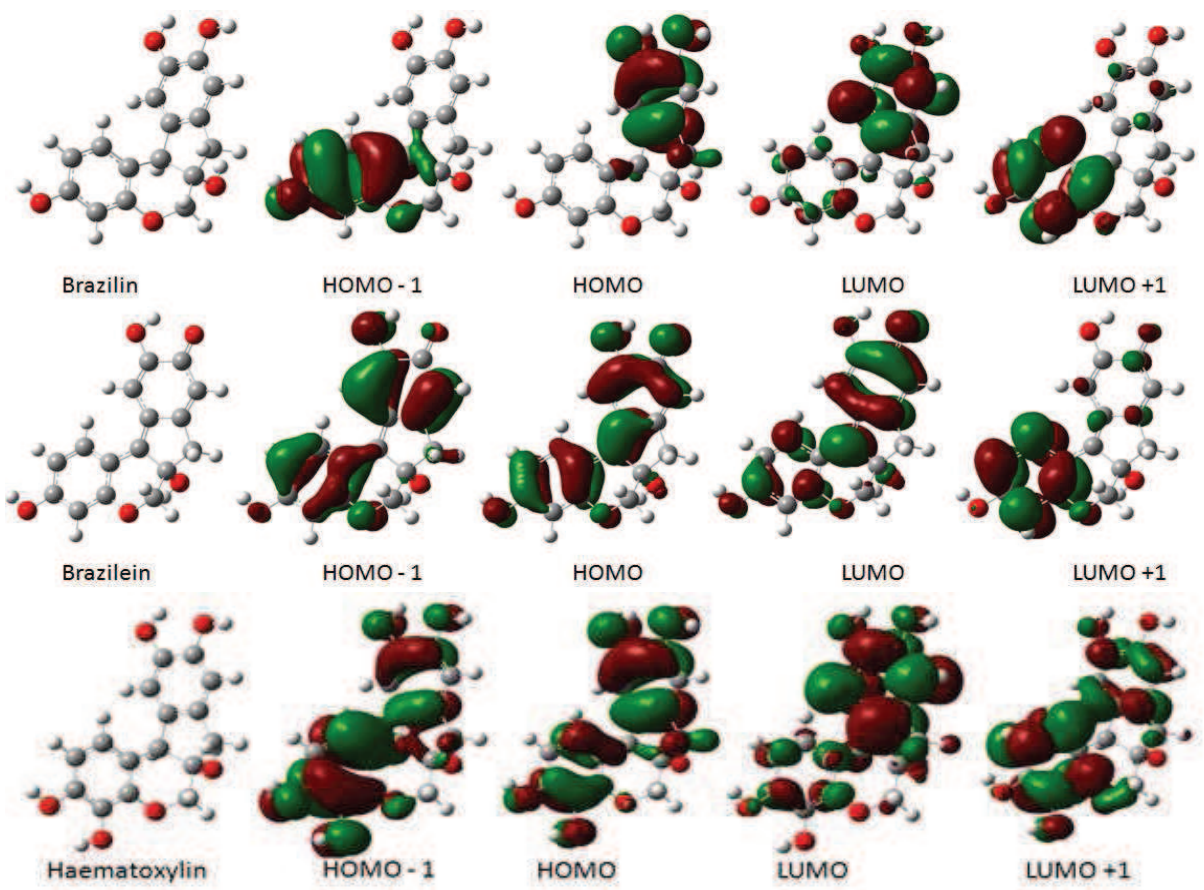

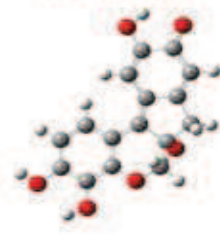

Haematein

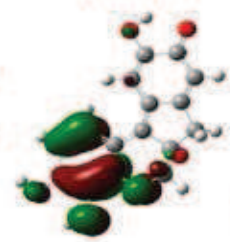

HOMO- 1

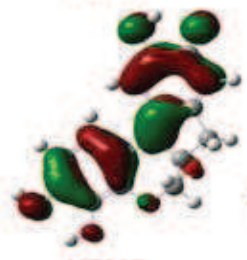

HOMO
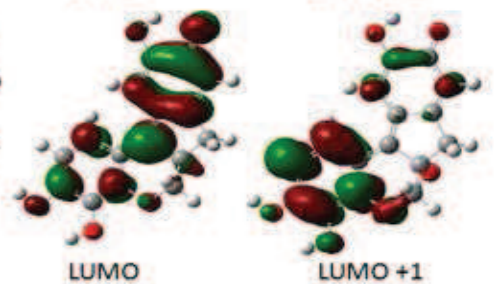

Figure 3: Electron structures of the dyes, at various energy levels. Models were visualized using GaussView 5 at isovalue of density $=0.03$ 
Haematoxylin consists of a 3,4-dihydro- $2 H$-chromen3,6,7-triol unit (CMT) and an IDD unit. Delocalization of the electron clouds was observed for HOMO -1 , HOMO, LUMO and LUMO +1 level. HOMO -1 and HOMO level electron clouds are $\pi$-type, whereas LUMO and LUMO +1 are $\pi^{*}$-type. The density of the electron clouds was observed to be higher in the IDD unit of LUMO while it was higher in the CMT unit at LUMO + 1 level. With a dense electron cloud localized close to the anchoring group (H2 hydroxyl group) during LUMO, electron transfer to the metal oxide semiconductor is favourable for $\mathrm{HOMO} \rightarrow$ LUMO transition.

Haematein consists of a CMT unit and a HDI unit. Localization of $\pi$-type electron at the CMT unit was observed at HOMO -1, while at HOMO level delocalization of the $\pi$-type electron cloud was observed over the entire molecule. At LUMO level, $\pi^{*}$-type electron clouds are delocalized over the entire molecule. As the anchoring group (H4 hydroxyl group) is covered by electron clouds at LUMO level, electrons can be injected into the metal oxide semiconductor. Lastly, at LUMO +1 level, the $\pi^{*}$-type electron cloud was localized in CMT unit, and with lower density of electron cloud localized at the 2-hydroxylcyclohexa-2,5-dien-1one unit of HDI unit exposing the cyclopentene ring.

When taking both the deprotonation energies and the electronic structure into account, it is possible to deduce which particular anchoring group of the molecule is the most favourable (Ekanayake et al., 2013). The hydroxyl anchoring group with the lowest deprotonation energy of brazilin, haematoxylin and their oxidized analogues are covered with electron clouds at LUMO level, thus these anchoring groups are deduced to be the most profitable to attach to the metal-oxide semiconductor.

\section{CONCLUSION}

All four dyes displayed a $\mathrm{HOMO} \rightarrow$ LUMO transition at the first excitation state. The hydroxyl groups of the dyes brazilin, brazilein, haematoxylin and haematein that have a potential to anchor to the semiconductor are H2, H3, H2 and H4 group, respectively. At LUMO level, the electron clouds of all four dyes appear near or at the anchoring group of the dyes, which facilitates electron injection into the metal oxide semiconductor. The LUMO of all four dyes is higher than the conduction band edge of $\mathrm{TiO}_{2}$, which is favourable for efficient electron injection. The HOMO level of the four dyes is lower than the redox couples $\left(\mathrm{I}^{-} / \mathrm{I}^{3-}\right)$, which helps to regenerate the dye. Of the four dyes investigated, the analysis of calculated optical properties revealed that brazilein and haematein have the potential as sensitizers in dye sensitized solar cells.

\section{Acknowledgement}

Universiti Brunei Darussalam (UBD) research grant UBD/PNC2/2/RG/1(176) and Brunei Research Council Science and Technology research grant (S \& T 17) are acknowledged for financial support.

\section{REFERENCES}

1. Baek N.I., Jeon S.G., Ahn E.M., Hahn J.T., Bahn J.H., Jang J.S., Cho S.W., Park J.K. \& Choi S.Y. (2000). Anticonvulsant compounds from the wood of Caesalpinia sappan L.. Archives of Pharmacal Research 23: 344 - 348.

DOI: http://dx.doi.org/10.1007/BF02975445

2. Bettinger C. \& Zimmermann H.W. (1991). New investigations on hematoxylin, hematein, and hemateinaluminium complexes. Histochemistry 96: 215 - 228. DOI: http://dx.doi.org/10.1007/BF00271540

3. Calogero G., Sinopoli A., Citro I., Di Marco G., Petrov V., Diniz A.M., Parola A.J. \& Pina F. (2013). Synthetic analogues of anthocyanins as sensitizers for dye-sensitized solar cells. Photochemical and Photobiological Sciences 12: $883-894$.

DOI: http://dx.doi.org/10.1039/c3pp25347c

4. Culling C.F.A. (1963). Handbook of Histopathological Techniques: (Including Museum Technique). Butterworths, London, UK.

5. Dennington R., Keith T. \& Millam J. (2009). Semichem Inc., Shawnee Mission, USA.

6. Deppmeier B., Driessen A., Hehre T., Hehre W., Johnson J., Klunzinger P., Leonard J., Ohlinger W., Pham I. \& Pietro W. (2011). Wavefunction Inc, Irvine, CA.

7. Dong S.K., Nam-In B., Sei R.O., Keun Y.J., Im S.L. \& Hyeong-Kyu L. (1997). NMR assignment of brazilein. Phytochemistry. The International Journal of Plant Biochemistry and Molecular Biology 46: 177 - 178.

8. Ekanayake P., Kooh M.R.R., Kumara N.T.R.N., Lim A., Petra M.I., Voo N.Y. \& Lim C.M. (2013). Combined experimental and DFT-TDDFT study of photo-active constituents of Canarium odontophyllum for DSSC application. Chemical Physics Letters 585: 121 - 127. DOI: http://dx.doi.org/10.1016/j.cplett.2013.08.094

9. Frisch M.J. et al. (72 authors) (2010). Gaussian, Inc., Wallingford, USA .

10. Gulmini M., Idone A., Diana E., Gastaldi D., Vaudan D. \& Aceto M. (2013). Identification of dyestuffs in historical textiles: strong and weak points of a non-invasive approach. Dyes and Pigments 98: $136-145$.

DOI: http://dx.doi.org/10.1016/j.dyepig.2013.02.010

11. Heera T.R. \& Cindrella L. (2010). Molecular orbital evaluation of charge flow dynamics in natural pigments based photosensitizers. Journal of Molecular Modeling 16: $523-533$.

DOI: http://dx.doi.org/10.1007/s00894-009-0569-z

12. Ishii H., Koyama H., Hagiwara K., Miura T., Xue G., Hashimoto Y., Kitahara G., Aida Y. \& Suzuki M. (2012). Synthesis and biological evaluation of deoxy-hematoxylin derivatives as a novel class of anti-HIV-1 agents. Bioorganic 
and Medicinal Chemistry Letters 22: 1469 - 1474.

DOI: http://dx.doi.org/10.1016/j.bmcl.2011.06.066

13. Karapanagiotis I., Mantzouris D., Kamaterou P., Lampakis D. \& Panayiotou C. (2011). Identification of materials in post-Byzantine textiles from Mount Athos. Journal of Archaeological Science 38: 3217 - 3223.

DOI: http://dx.doi.org/10.1016/j.jas.2011.06.022

14. Kim B., Kim S.H., Jeong S.J., Sohn E.J., Jung J.H., Lee M.H. \& Kim S.H. (2012). Brazilin induces apoptosis and $\mathrm{G} 2 / \mathrm{M}$ arrest via inactivation of histone deacetylase in multiple myeloma U266 cells. Journal of Agricultural and Food Chemistry 60: 9882 - 9889. DOI: http://dx.doi.org/10.1021/jf302527p

15. Lee J.K. \& Yang M. (2011). Progress in light harvesting and charge injection of dye-sensitized solar cells. Materials Science and Engineering: B 176: $1142-1160$. DOI: http://dx.doi.org/10.1016/j.mseb.2011.06.018

16. Liu Z. (2008). Theoretical studies of natural pigments relevant to dye-sensitized solar cells. Journal of Molecular Structure: THEOCHEM 862: $44-48$. DOI: http://dx.doi.org/10.1016/j.theochem.2008.04.022

17. Livingstone R. (1987). Anthocyanins, brazilin, and related compounds. Natural Product Reports 4: 25 - 33. DOI: http: //dx.doi.org/10.1039/np9870400025

18. Melo M.J. (2009). Handbook of Natural Colorants (eds. T. Bechtold \& R. Mussak). John Wiley \& Sons Ltd., New York, USA.

19. Narayan M.R. (2012). Review: dye sensitized solar cells based on natural photosensitizers. Renewable and Sustainable Energy Reviews 16: 208 - 215.

DOI: http://dx.doi.org/10.1103/PhysRevB.86.201402

20. O'regan B. \& Grätzel M. (1991). A low-cost, high-efficiency solar cell based on dye-sensitized. Nature 353: 24. DOI: http://dx.doi.org/10.1038/353737a 0

21. Puchtler H., Meloan S.N. \& Waldrop F.S. (1986). Application of current chemical concepts to metal-hematein and-brazilein stains. Histochemistry 85: $353-364$. DOI: http://dx.doi.org/10.1007/BF00982665

22. Qin C. \& Clark A.E. (2007). DFT characterization of the optical and redox properties of natural pigments relevant to dye-sensitized solar cells. Chemical Physics Letters 438: $26-30$.

DOI: http://dx.doi.org/10.1016/j.cplett.2007.02.063

23. Rosenberg E. (2008). Characterisation of historical organic dyestuffs by liquid chromatography-mass spectrometry.
Analytical and Bioanalytical Chemistry 391: $33-57$.

DOI: http://dx.doi.org/10.1007/s00216-008-1977-0

24. Sastry C.S.P., Satyanarayana P., Rao A.R. \& Singh N.R.P. (1989). Oxidized haematoxylin, a new reagent for the spectrophotometric determination of penicillins and cephalosporins. Microchimica Acta 97: 17 - 24.

DOI: http://dx.doi.org/10.1007/BF01197279

25. Tong X.Z., Zhu H., Shi Y., Xu H.T., Wang B. \& Zhao J.H. (2014). An LC/MS/MS method for simultaneous quantitation of two homoisoflavones: protosappanin B and brazilin with hypoglycemic activity in rat plasma and its application to a comparative pharmacokinetic study in normal and streptozotocin-treated rats. Journal of Ethnopharmacology 148 (2): 682 - 690.

DOI: http://dx.doi.org/10.1016/j.jep.2013.05.029

26. Wang J., Cong S., Wen S., Yan L.K. \& Su Z.M. (2013). A rational design for dye-sensitizer: density functional theory study on the electronic absorption spectra of organoimido-substituted hexamolybdates. The Journal of Physical Chemistry C 117: 2245 - 2251.

DOI: http://dx.doi.org/10.1021/jp3106452

27. Weigl M., Kandelbauer A., Hansmann C., Pöckl J., Müller U. \& Grabner M. (2009). Handbook of Natural Colorants (eds. T. Bechtold \& R. Mussak), pp. 277 - 313. John Wiley $\&$ Sons Ltd., New York, USA.

DOI: http://dx.doi.org/10.1002/9780470744970.ch17

28. Wu S.Q., Otero M., Unger F.M., Goldring M.B., Phrutivorapongkul A., Chiari C., Kolb A., Viernstein H. \& Toegel S. (2011). Anti-inflammatory activity of an ethanolic Caesalpinia sappan extract in human chondrocytes and macrophages. Journal of Ethnopharmacology 138: $364-$ 372. DOI: http://dx.doi.org/10.1016/j.jep.2011.09.011

29. Ye M., Xie W.D., Lei F., Meng Z., Zhao Y.N., Su H. \& Du L.J. (2006). Brazilein, an important immunosuppressive component from Caesalpinia sappan L.. International Immunopharmacology 6: 426 - 432 .

DOI: http://dx.doi.org/10.1016/j.intimp.2005.09.012

30. Yella A., Lee H.W., Tsao H.N., Yi C., Chandiran A.K., Nazeeruddin M.K., Diau E.W.G., Yeh C.Y., Zakeeruddin S.M. \& Grätzel M. (2011). Porphyrin-sensitized solar cells with cobalt (II/III) based redox electrolyte exceed 12 percent efficiency. Science 334: $629-634$. DOI: http://dx.doi.org/10.1126/science.1209688 